\title{
Glasgow Coma Scale and Full Outline of Unresponsiveness Score Instruments to Determine Patient Outcome: A Systematic Review
}

\author{
Ika Silvitasari, Wahyuni
}

School of Health Sciences Aisyiyah, Surakarta, Central Java

\begin{abstract}
Background: Glasgow Coma Scale (GCS) and Full Outline of Unresponsiveness Score (FOUR score) are instruments to determine the level of patient consciousness. These instruments require good sensitivity and specificity, so that they can be used quickly and easily. This study aimed to determine the validity and reliability of GCS and FOUR score instruments in determining adult patient outcome.

Subjects and Method: This study was a systematic review study. The search for the articles involved the client population treated in the ICU, Emergency Installation and neurology room, patients who did not receive sedation or neuro blockers, were observed by health workers. The outcomes were in the form of death of patients in the hospital, mRS, Glasgow outcome score, and APACHE II. This study were carried out using EBSCO, Sciencedirect, Pubmed, and Google Scholar, restricted articles from 2007-2017, and observational study. The number of articles that was in accordance with the inclusion and exclusion criteria for this study was 9 articles. All articles found were used as sample.
\end{abstract}

Results: The average sensitivity and specificity values of the GCS instrument and FOUR Score were close to 1 or $100 \%$. From the 8 articles found, all got sensitivity and specificity values by $>50 \%$.

Conclusion: The FOUR instrument score can be used as a substitute for GCS to assess the level of patient consciousness with patient outcomes (death) in ICU.

Keywords: glasgow coma scale, full outline of unresponsiveness score, outcome

\section{Correspondent:}

Ika Silvitasari. School of Health Sciences Aisyiyah, Surakarta, Central Java. Jl. Ki Hajar Dewantara 10, Surakarta 57126, Central Java. Email: mouse_o2april@yahoo.com.

\section{BACKGROUND}

Consciousness is a condition where a person is able to make real contact with an object in order to interact with oneself and the environment (Bordini et al. 2010; Porth 2011; Smeltzer et al. 2010). The level of consciousness is a sensitive indicator of neurological function, so that the assessment of the consciousness level is needed (Smeltzer et al. 2010). An assessment of the level of consciousness can determine the prognosis of improvement or deterioration of the patient's condition in the intensive care room. The prediction of the condition can be used to improve the management of nursing care in patients to be more optimal; besides, it improves motivation to provide more optimal care (Dewi et al. 2011)

This study used GCS as the instrument to measure the level of consciousness in general. This instrument was considered simple to use. Besides, it has been tested for validity and reliability. The GCS instrument was initially introduced by Jennett $B$ and Teasdale $\mathrm{G}$ consisting of three components namely the eye, motor, and verbal components (Bordini et al. 2010). The three components in the instrument have different 
values in each component. The result of the assessment using this instrument have not been able to facilitate the assessment of intubated patients, namely the verbal component is difficult to assess (Irawan, Setiawan, and Dewanto 2009; Jalali and Rezaei 2014; Tadrisi et al. 2012).

Due to the limitation in the GCS component, new components were needed to improve it. The new instrument introduced by Widjick was called the Full Outline of Unresponsiveness (FOUR) score. It completes the GCS component, where the instrument component consists of the eye, motor, brain stem, and respiration with the same value in each component (Stead et al. 2009; Wijdicks et al. 2005).

Several diagnostic test studies showed different results on the sensitivity and specificity values between GCS and FOUR scores. Based on a study conducted by Jalali and Rezaei (comparing the GCS scale and FOUR score in patients with brain injury in the ICU room), the sensitivity value between GCS and FOUR score was same $(68.4 \%=68.4 \%)$. Besides, the GCS specificity value was lower than the FOUR score $(63.6 \%<77.3 \%)$ with patient mortality outcome in hospital (Jalali And Rezaei, 2014). However, it was different with the result of a study conducted by Peng-Juan et al. on the validation of the Chinese version of FOUR score in patients with neurological disorders. Based on the result of the study, the GCS sensitivity value was higher than FOUR score $(83 \%>79 \%)$. In addition, the specificity value of GCS was lower than FOUR score $(72 \%<74 \%)$ with patient mortality outcome in hospital (Peng $\mathrm{J}$ et.al, 2015). The study aims to determine the sensitivity value and the specificity of the GCS and FOUR score instruments on adult patient outcome

\section{SUBJECTS AND METHOD}

\section{Study Design}

This was a systematic review. This study used PRISMA (Preferred Reporting Items for Systematic Reviews and Meta-analysis) method which was carried out systematically by following the correct stages or study protocols. This search for the articles was conducted from August 2015-July 2016. This database search was carried out by searching journals in several international and national electronic journals accessed through Diponegoro University database. They were EBSCO, Sciencedirect, Pubmed, and Google Scholar with selected keywords. If there were the same journals on an electronic journal, one journal would be selected. The keywords used are FOUR score, GCS, adult patient, unconsciousness, validity reliability, coma scale, Glasgow Coma Scale, consciousness and Full Outline of Unresponsiveness.

\section{The characteristics of inclusion and exclusion criteria}

The study design for the systematic review was an observational study. It aimed to determine the sensitivity and specificity of GCS and FOUR scores in patients with decreased level of consciousness in the ICU, who met the inclusion and exclusion criteria. The inclusion criteria were: (1) Type of participants was limited by age, namely adult patients that were treated in the emergency room or ICU that did not receive sedation drugs; (2) Level of consciousness of the participants were measured using the GCS and FOUR score instruments, and the outcome measured was the death of the patient in the hospital; and (3) Articles were limited by journal publication years, namely from 2007 to 2017 or 10 years for the maximum years. Besides, articles that were selected were full text articles. 


\section{Data Analysis}

The quality of the article was examined using the critical appraisal instrument from CASP (Critical Appraisal Skills Program). It was summarized in a table consisting of title, year, author name, instrument, sample, study design, and study results (CASP, 2013).
Based on the result of the search for articles that have been carried out, there were 48 articles. 9 articles that fit the inclusion and exclusion criteria were analyzed. All articles were observational study with cross-sectional design. The articles found were described in Figure 1.

48 full text articles were found.

(18) EBSCO, (5) Sciencedirect, (3) Pubmed,

(22) google scholar.
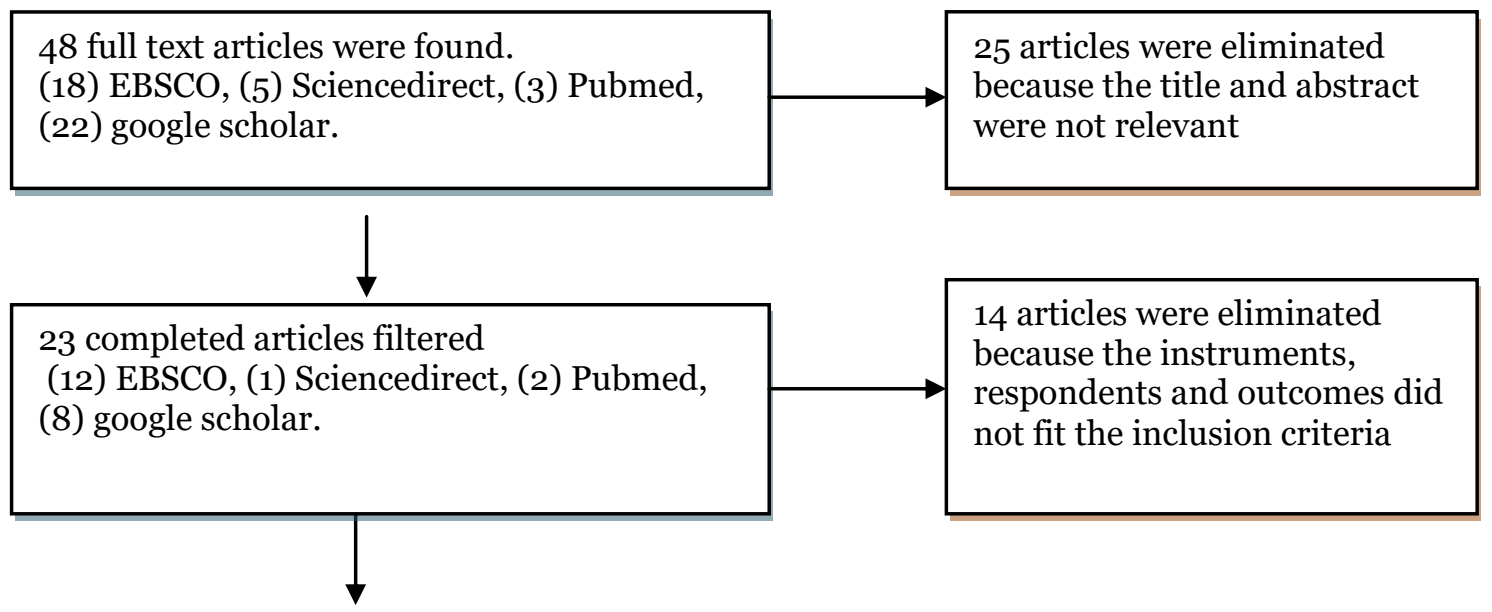

9 completed articles that were considered to meet the inclusion requirements.(5) EBSCO, (1) Sciencedirect, (2) Pubmed, and (1) google scholar.

\section{Figure 1. The flow of the search for the article}

\section{RESULTS}

\section{A.Selection of the Article}

Based on the result of the analysis of the quality of articles using CASP, almost all articles met the criteria contained in the CASP assessment of check list of Clinical Prediction format. All articles have good quality. It could be seen from the methodology and outcome in the article.

Based on the result of data extraction, the sensitivity and specificity values for GCS and FOUR scores instruments were different. There were 9 articles that showed the sensitivity and specificity values towards population, cut-off values, and different results for each article. The sensitivity and specificity values of the GCS and FOUR
Score instruments were summarized in the data extraction in Table 1.

6 out of 9 articles showed that sensitivity value of FOUR score was higher than GCS and specificity value of FOUR score was higher than GCS. Seven studies were conducted in patients with neurological disorders both in patients with brain trauma, neurosurgery, ischemic stroke, and head injury. One study was conducted in a population in patients with multiple traumas. In addition, another study was conducted in all cases. Three studies were conducted in China and Indonesia. Based on the result, the sensitivity and specificity of FOUR score was higher than GCS. 


\section{Table 1. The Result of the Data Extraction}

\begin{tabular}{|c|c|c|c|}
\hline Author & Population & Cut off value & Result \\
\hline $\begin{array}{lll}\text { Jalali } & \mathrm{R} & \text { and }\end{array}$ & Brain injury in ICU of Teleghani & $\mathrm{GCS}=5$ & Sensitivity 0.684; specificity 0.636 \\
\hline Rezaei M, 2014 & Hospital & FOUR score $=6$ & Sensitivity 0.684 ; specificity 0.773 , with prediction of death in the hospital. \\
\hline Elco $\quad \mathrm{F} \quad \mathrm{M}$, & Patients with neurological disorders at & $\mathrm{GCS}=7$ & Sensitivity 0.80 ; specificity 0.80 \\
\hline $\begin{array}{l}\text { Wijdick, E F M. } \\
\text { et.al, } 2005\end{array}$ & Mayo clinic, America. & FOUR score $=9$ & Sensitivity 0.75 ; specificity 0.76 , with prediction of death in the hospital. \\
\hline \multirow{2}{*}{$\begin{array}{l}\text { Akavipat P. et. } \\
\text { al, } 2011\end{array}$} & Patients with neurological disorders at & FOUR score $=14$ & Sensitivity 0.77; specificity 0.95 \\
\hline & Prasat Neurological Institute & FOUR score $=10$ & Sensitivity 0.71 ; specificity 0.93 , with prediction of death in the hospital. \\
\hline \multirow{2}{*}{$\begin{array}{l}\text { Mansour } \mathrm{O} \quad \mathrm{Y} \\
\text { et.al, 2015 }\end{array}$} & Ischemic stroke in ICU of Alexandria & $\mathrm{GCS}=7$ & GCS : Sensitivity 0.96;spesifisitas 0.92 \\
\hline & hospital & FOUR score $=8$ & $\begin{array}{l}\text { FOUR score Sensitivity } 1 \text {; specificity } 0.86 \text { ), in predicting the mortality rate of } \\
\text { patients in the hospital }\end{array}$ \\
\hline \multirow{4}{*}{$\begin{array}{l}\text { Peng-Juan et.al } \\
2015\end{array}$} & Neurosurgery patient in the ICU of & $\mathrm{GCS}=7$ & Sensitivity $0.63 ;$ specificity 0.89 \\
\hline & Nanfang Hospital & FOUR score $=9$ & Sensitivity 0.75 ; specificity 0.85 , with prediction of death in hospital. \\
\hline & & $\mathrm{GCS}=10$ & Sensitivity 0.83 ; specificity 0.72 \\
\hline & & FOUR score $=13$ & Sensitivity 0.79 ; specificity 0.74 , with prediction of death in hospital. \\
\hline \multirow{2}{*}{$\begin{array}{l}\text { Baratloo } \\
2015\end{array}$} & Multiple trauma in the Emergency & & GCS : Sensitivity o.842; specificity 0.886 \\
\hline & $\begin{array}{l}\text { Installation at Sohadaye Tajrish } \\
\text { Hospital }\end{array}$ & & $\begin{array}{l}\text { FOUR score: Sensitivity } 0.869 \text {; specificity } 0.884 \text {, with prediction of death in } \\
\text { the hospital at the beginning of treatment. } \\
\text { GCS : Sensitivity } 0.895 \text {; specificity } 0.954 \\
\text { FOUR score: Sensitivity 0.895; specificity 1, with prediction of death in the } \\
\text { hospital for } 6 \text { hours of treatment. }\end{array}$ \\
\hline Gorji & Brain Injury trauma in the ICU room at & $\mathrm{GCS}=4$ & Sensitivity $0.85 ;$ specificity 0.78 \\
\hline $\begin{array}{l}\text { Mohammad et. } \\
\text { al. } 2014\end{array}$ & $\begin{array}{l}\text { Mazandaran University of Medical } \\
\text { Science }\end{array}$ & FOUR score $=4$ & Sensitivity 0.92: specificity 0.87 , with prediction of death in hospital. \\
\hline \multirow[t]{2}{*}{ Tua Marlon 2014} & Head Injury in the & GCS $=9,5$ & Sensitivity 0.889 ; specificity 0.914 \\
\hline & Installation, Indonesia & FOUR score $=11,5$ & $\begin{array}{l}\text { Sensitivity } 0.944 \text {; specificity } 0.962 \text {, with prediction of death for } 7 \text { days of } \\
\text { treatment in the hospital. }\end{array}$ \\
\hline $\begin{array}{l}\text { Silvitasari, } \\
\text { Sujianto, } \\
\text { Purnomo; } 2017\end{array}$ & $\begin{array}{l}\text { Patients with decreased level of } \\
\text { consciousness in the ICU }\end{array}$ & $\begin{array}{l}\text { GCS }=5 \\
\text { FOUR score }=6\end{array}$ & $\begin{array}{l}\text { GCS: sensitivity } 0.722 \text {; specificity } 0.737 \text {. } \\
\text { FOUR score: sensitivity } 0.861 \text {; specificity } 0.816 \text {, with prediction of outcome } \\
\text { (death) of patients in ICU. }\end{array}$ \\
\hline
\end{tabular}




\section{DISCUSSION}

Instrument of the study is a tool used by a Author to observe, measure, and assess phenomena. Therefore, the study activities can be systematic and easy to do. An instrument is good if it can measure what should be measured (validity), produces the same value on repeated checks (reliable), has the same value on each component (linear), has simple instructions without any tools (easy to use), and can predict the outcome or the future (Dharma, 2011).

The difference in sensitivity and specificity between FOUR score and GCS instruments showed that the sensitivity and specificity of FOUR score was higher than GCS. 6 out of 9 studies showed that sensitivity value of FOUR score was higher than GCS and specificity value of FOUR score was higher than GCS. The result of this systematic review showed that the FOUR score instrument could be used as a substitute for the GCS instrument in assessing the level of consciousness towards the outcome of patients who lived or died.

Based on the study result conducted by Silvitasari et al. (2016) in the ICU room without specifying specific diseases, the sensitivity and specificity of FOUR Score was higher than GCS. Therefore, these results were able to represent the level of consciousness of all patients in ICU with outcome of patients who lived or died for 7 days of treatment. Based on the result of the previous study towards the population, seven studies were conducted in patients with neurological disorders both in patients with brain trauma, neurosurgery, ischemic stroke, and head injury. In addition, one study was conducted towards patients with multiple traumas. As a result, the previous studies have not been able to represent the generalization of the use of GCS and FOUR scores instruments.
This FOUR instrument was created to facilitate and speed up the assessment of the level of patient consciousness where the neurological components needed in GCS do not exist (Steade et.al, 2009). An instrument is good if the diagnostic value of the instrument is better, cheaper, the examination is not invasive, can be carried out faster and simpler, and easier to do (Bhisma, 2018).

The assessment of the level of consciousness with the right result can help families and health workers in providing treatment, monitoring the condition of the development of patient health, providing comfort and simplicity of administration, and reduce the hospital cost (Bruno, 2011). Clinically, the errors in assessing the level of consciousness cause misdiagnosis; it has an effect on management and therapeutic errors (Bruno et al. 2011).

Based on this systematic review, the sensitivity and specificity of the GCS and FOUR score instruments had good results. The average of the result of the validity of the instrument showed good to very good results to assess the outcome in the form of patient mortality with a value by $>50 \%$, close to 1 , or $100 \%$. Further study needs to be conducted to find out the new cut-off values for the two instruments in order to strengthen the results of this study, especially study that is carried out in Indonesia.

\section{AUTHOR CONTRIBUTIONS}

Ika Silvitasari, Wahyuni examine GCS instrument and FOUR Score, did the data analysis, interpreted the results of data analysis, and wrote the manuscript.

\section{CONFLICT OF INTEREST}

We declare that we do not have any conflict of interest. 
Indonesian Journal of Medicine (2019), 4(4): 339-345

https://doi.org/10.26911/theijmed.2019.04.04.06

FUNDING AND SPONSORSHIP

There is no external fund and sponsorship.

\section{REFERENCE}

Bordini AL, Luiz TF, Fernandes M, Arruda WO, Teive HAG (2010). Coma scales A historical review. Arq Neurosiquiart 68(May):930-7. Doi: 10.1590/sooo4282x2010000600019.

Bruno M-A, Ledoux D, Lambermont B, Damas F, Schnakers C, Vanhaudenhuyse A, et al (2011). Comparison of the Full Outline of UnResponsiveness and Glasgow Liege Scale/Glasgow Coma Scale in an intensive care unit population. Neurocrit Care, 15(3): 447-53. doi: 10.1007/s12028-011-9547-2.

Critical Appraisal Skill Program (2013). Critical appraisal skill program making sense of evidence. CASP UK.

Dharma K (2011). Metodologi Penelitian Keperawatan. Jakarta: CV Trans Info Media.

Dewi R, Mangunatmadja, Irawan, Yuniar I (2011). Perbandingan full outline of unresponsiveness score dengan glasgow coma scale dalam menentukan prognostik pasien sakit kritis. Sari Pediatr, 13(3).

Silvitasari I, Purnomo H, Sujianto U (2016). Sensitivity and specificity of full outline of unresponsiveness score and glasgow coma scale towards patients' outcomes at the intensive care units. IOSR Journal of Nursing and Health Science (IOSR-JNHS), 5(4): 10-13. Doi: 10.9790/1959-0601031013 .

Irawan H, Setiawan F, Dewanto G (2009). Perbandingan glasgow coma scale dan revised trauma score dalam memprediksi disabilitas pasien trauma kepala di Rumah Sakit Atma Jaya, 437-42.
Jalali R, Rezaei M (2014). A Comparison of the Glasgow Coma Scale Score with Full Outline of Unresponsiveness Scale to Predict Patients ' Traumatic Brain Injury Outcomes in Intensive Care Units. Hindawi Publishing Corporation. Critical Care Research and Practice. Volume 2014, Article ID 289803, 4 pages. Retrieved from http://dx.doi.org/10.1155/2014/289803.

Murti B (2018). Prinsip dan metode riset epidemiologi. Edisi ke 4. Surakarta: Program Studi Ilmu Kesehatan Masyarakat, Program Pascasarjana, Universitas Sebelas Maret.

Peng J, Deng Y, Chen F, Zhang X, Wang X, Zhou Y, et al (2015). Validation of the Chinese version of the FOUR score in the assessment of neurosurgical patients with different level of consciousness. BMC Neurol: 1-8. doi: 10.1186/s12883-015-0508-9

Porth C (2011). Essentials of pathophysiology: concepts of altered health states. Edisi 3. Wolters Kluwer Health | Lippincott Williams \& Wilkins.

Smeltzer, Suzanne C, Bare, Brenda G (2010). Brunner \& Suddarth's textbook of medical-surgical nursing. Edisi 12. Wolters Kluwer Health / Lippincott Williams \& Wilkins.

Stead LG, Wijdicks EFM, Bhagra A, Kashyap R, Bellolio MF, Nash DL, et al (2009). Validation of a new coma scale, the FOUR score, in the emergency department. Neurocrit Care, 10(1):50-4. Doi: 10.1007/s12028-008-9145-0

Tadrisi SD, Bahari N, Ebadi A, Madani SJ (2012). Validity and reliability of coma scale (four score) in adult patient hospitalized in Critical Care Units. Critical Care Units. Critical Care Nursing. 5(13): $95-100$. 
Silvitasari et al./ Glasgow Coma Scale and Full Outline of Unresponsiveness Score

Wijdicks EFM, Bamlet WR, Maramattom B V, Manno EM, McClelland R (2005). Validation of a new coma scale: The
FOUR score. Ann Neurol. 58(4): 58593. Doi: 10.1002/ana.20611 